\title{
Bilateral microtia-deafness-cleft palate syndrome
}

INSERM

\section{Source}

INSERM. (1999). Orphanet: an online rare disease and orphan drug data base. Bilateral microtia-deafness-cleft palate syndrome. ORPHA:140963

This syndrome is characterized by the association of bilateral microtia with severe to profound hearing impairment, and cleft palate. 